\title{
Screw Withdrawal Resistance of Moulded Laminated Veneer Oil Palm (MLVOP) Bonded with Formaldehyde Resins
}

\author{
Abdul Hamid Saleh ${ }^{1}$, Abdul Khalil Shawkataly ${ }^{2}$, Ahmad Shakri bin Mat Seman ${ }^{3}$, Izran Kamal ${ }^{4}$, Noor Azrieda \\ Abdul Rashid ${ }^{5} \&$ Siti Zalifah Mahmud ${ }^{6}$ \\ ${ }^{1}$ Furniture Design Laboratory, Forest Research Institute Malaysia (FRIM) 52109, Kepong, Selangor Darul \\ Ehsan, Malaysia \\ ${ }^{2}$ Bioresource, Paper and Coating Technology, School of Industrial Technology (PPTI), Universiti Sains Malaysia \\ (USM), Pulau Pinang 11800, Malaysia \\ ${ }^{3}$ Department of Civil Engineering Technology, Faculty of Civil and Environmental Engineering, Universiti Tun \\ Hussein Onn Malaysia (UTHM), Parit Raja 86400, Batu Pahat, Johor Darul Takzim, Malaysia \\ ${ }^{4}$ Timber Technology Centre, Forest Research Institute Malaysia (FRIM), Kepong 52109, Selangor Darul Ehsan, \\ Malaysia \\ ${ }^{5}$ Wood Mycology Laboratory, Forest Research Institute Malaysia (FRIM), Kepong 52109, Selangor Darul Ehsan, \\ Malaysia \\ ${ }^{6}$ Faculty of Applied Science, Universiti Teknologi Mara (UiTM), Bandar Tun Abdul Razak 26400, Jengka, \\ Pahang Darul Makmur, Malaysia
}

Correspondence: Abdul Hamid Saleh, Furniture Design Laboratory, Forest Research Institute Malaysia (FRIM), Kepong 52109, Selangor Darul Ehsan, Malaysia. Tel: 60-3-6279-7382. E-mail: hamid@frim.gov.my

Received: March 21, 2012

Accepted: May 23, 2012 Online Published: May 30, 2012

doi:10.5539/mas.v6n6p112

URL: http://dx.doi.org/10.5539/mas.v6n6p112

\begin{abstract}
A research was conducted to discover the screw withdrawal resistance of moulded laminated veneer lumbers made from oil palm trunks (MLVOP). The MLVOPs were manufactured separately with three different veneer arrangements namely S100\% (each ply came from the superior part), SS-CI (surface superior and core inferior) and S-I (alternate superior and inferior parts). The veneers were divided into two groups. One group of veneers was bonded with urea formaldehyde (UF) resin to MLVOPs and the other was bonded with phenol formaldehyde $(\mathrm{PF})$. The veneers were pressed at a temperature of $110^{\circ} \mathrm{C}$ for $20 \mathrm{~min}$. The pressures applied to press the veneers to MLVOPs were $1500 \mathrm{psi}, 2000 \mathrm{psi}$ and $2500 \mathrm{psi}$. The study showed that the pressures and S-I veneer arrangement gave significant effects to the screw withdrawal resistance of UF-bonded and PF-bonded MLVOPs. MLVOPs with S-I veneer arrangement achieved the highest mean screw withdrawal resistance values when they were bonded with UF resin then pressed with 1500 psi and 2500 psi and bonded with PF resin and pressed with 1500 psi. The values were $848 \mathrm{~N}, 884 \mathrm{~N}$ and $496 \mathrm{~N}$ respectively. Overall, UF-bonded MLVOPs were better than those bonded with PF resin.
\end{abstract}

Keywords: veneer arrangement, MLVOP, pressure, UF resin, PF resin

\section{Introduction}

Until now, oil palm remains as one of the most popular commodities in Malaysia. In year 2007, about 4.2 hectares of Malaysia were reserved as oil palm plantation areas to ensure continuous supply to meet the increasing demand of oil palm. The establishment of plantation area seems increasing each year due to the endless demand on the agriculture trees. Currently, Malaysia covers about $45 \%$ of world's oil palm annual production and appears as the largest oil palm exporter and producer in the world (Jegatheswaran, 2011). Large volume of oil palm was involved to achieve such achievements. This causes production of large volume of oil palm biomass especially oil palm trunks which are frequently left at the harvesting sites as waste. Failure of utilizing the waste properly can cause pollution to the environment (Razak et al., 2008). Several researches had been conducted to find ways to utilize the agriculture waste, in order to prevent that situation from becoming worse. One of the researches revealed that oil palm trunks can be utilized for the production of laminated veneer lumber (Razak et al., 2008; Kamarulzaman et al., 2004). There are many benefits possessed by laminated veneer 
lumber. The advantages are: 1) It is stronger, straighter and more uniform, 2) Like other laminated finishes, laminated veneer lumber is stable which it is hard to warp, twist, bow and shrink (Buckley, 2011). The uniform properties and higher strength or laminated veneer lumber (LVL) made it as a superior structural material than other solid timber or glue laminated timber (Hng et al., 2007). It can be justified that through the advantages mentioned previously, utilizing oil palm trunks for producing laminated veneer lumber is not a wrong direction. Even though laminated veneer lumber is strong, however, in order to expand its usage especially as building construction material, studying its screw withdrawal resistance, especially when they are subjected to load is not an exception. The term screw withdrawal is defined as the measure of resistance to withdrawal in a plane normal to the face. The screw withdrawal resistance is influenced by density as well as internal bonding of a panel. Greater screw withdrawal resistance was observed from composites with higher density and stronger internal bonding (Eckelman, 1990). Factors that affect screw withdrawal resistance value are physical and mechanical properties, the size and the shape of the tested media. It is also affected by the surface condition of the screw (s), the speed of withdrawal, physical changes happen to the tested media or screws between time of driving and time of withdrawal, orientation of the fibre, and nature of prebored lead holes (the holes that are purposely made before the screws are threaded into the tested media) (ASTM D1761, 2006). In this report, screw withdrawal resistance in moulded laminated veneer lumber made of oil palm trunk (MLVOP) was investigated. The objective of the test was to evaluate the screw holding ability of the laminated veneer lumbers which were arranged with three different veneer arrangements and pressed with three different pressing pressures.

\section{Materials and Method}

Five oil palm trunks were obtained from Felda Trolak, Perak Darul Ridzuan, Malaysia (Figure 1). The initial dimensions of the OPTs were 16 inch to 24 inch diameters and 15 feet long. Since cross-sections of the trunks were uneven and caused uneven diameter value, hence the diameters were the means of diameters measured from two different points at the cross sections (Figure 2).

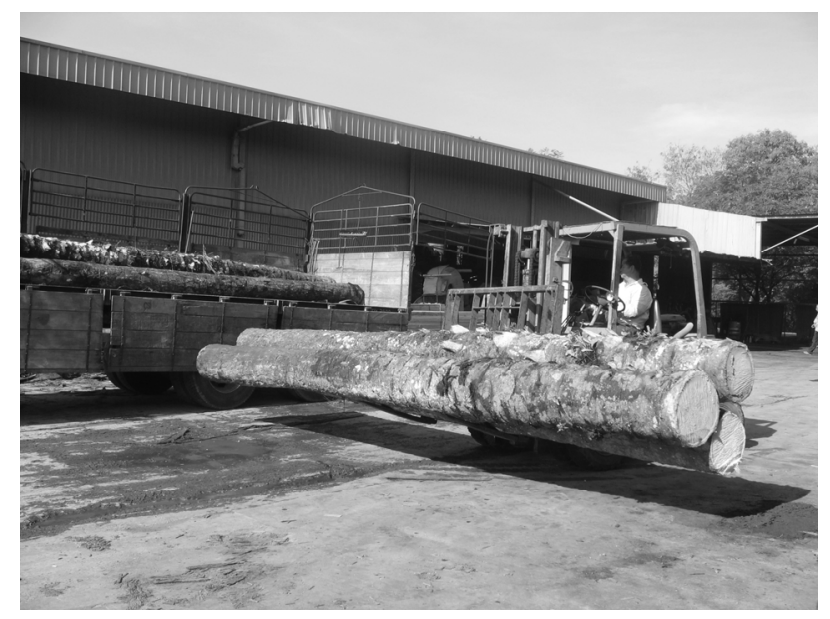

Figure 1. Unloading OPTs from a lorry

The trunks were processed to MLVOP at a factory, Kin Heng Timber Sdn. Bhd in Perak Darul Ridzuan. The formaldehyde resins used for the study were phenol formaldehyde (PF) and urea formaldehyde (UF). The PF and UF resins were formulated by following specifications for manufacture of weather-bond plywood and moisture-resistant plywood respectively. The resins were supplied by Malayan Adhesives and Chemicals Sdn Bhd. (MAC). 


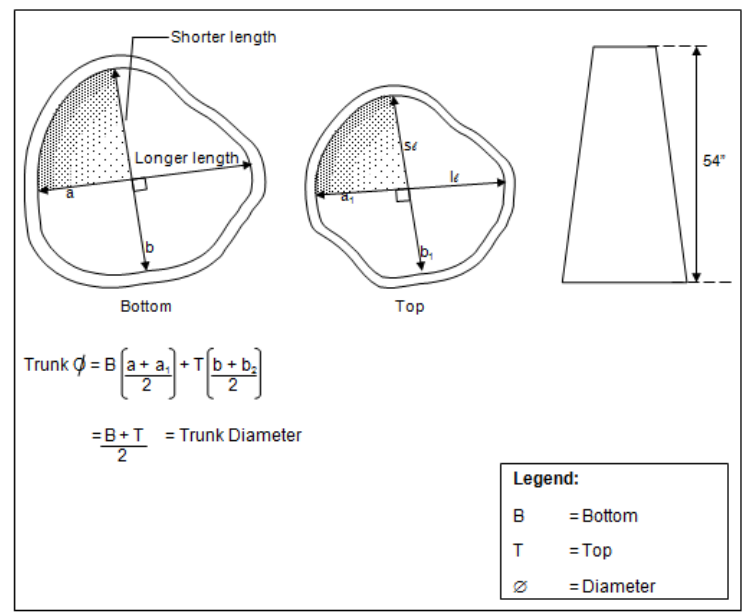

Figure 2. Diameter measurement

\subsection{Production of Moulded Laminated Veneer Oil Palm}

The initial moisture content (MC) of the oil palm trunks was $300 \%$ to $450 \%$. The oil palm trunks were debarked and cut into billets with a length of 54 inch $(137 \mathrm{~cm})$.

\subsection{Peeling Process}

The oil palm trunk billets were transformed to veneers through a process called peeling using spindles rotary peeler machine. One billet was peeled at a time. The veneers were categorized into two types: 1) superior and, 2) inferior. The superior veneers were produced by peeling the billet until the core of the billet left 10 inches in diameter (Figure 3). Then, with the same billet, further peeling was done until the core of the billet left 4 inches in diameter, which by this the inferior veneers were obtained (Figure 4). After the peeling process, the veneers were cut into a size of $2.0 \mathrm{ft} \times 4.0 \mathrm{ft}$ and were dried in a roller conveyer dryer with a set temperature from $60^{\circ} \mathrm{C}$ to $70^{\circ} \mathrm{C}$. The green $\mathrm{MC}$ of the OPT veneers was between $90 \%$ and $110 \%$. The temperature was initially set by the factory to dry wood veneer, therefore to decrease the MC to $6-9 \%$, the OPT veneers were dried in the conveyer dryer twice with that temperature. Each drying cycle required $25 \mathrm{~min}$. The thicknesses of the veneers after drying were between 3.0 to $3.5 \mathrm{~mm}$.

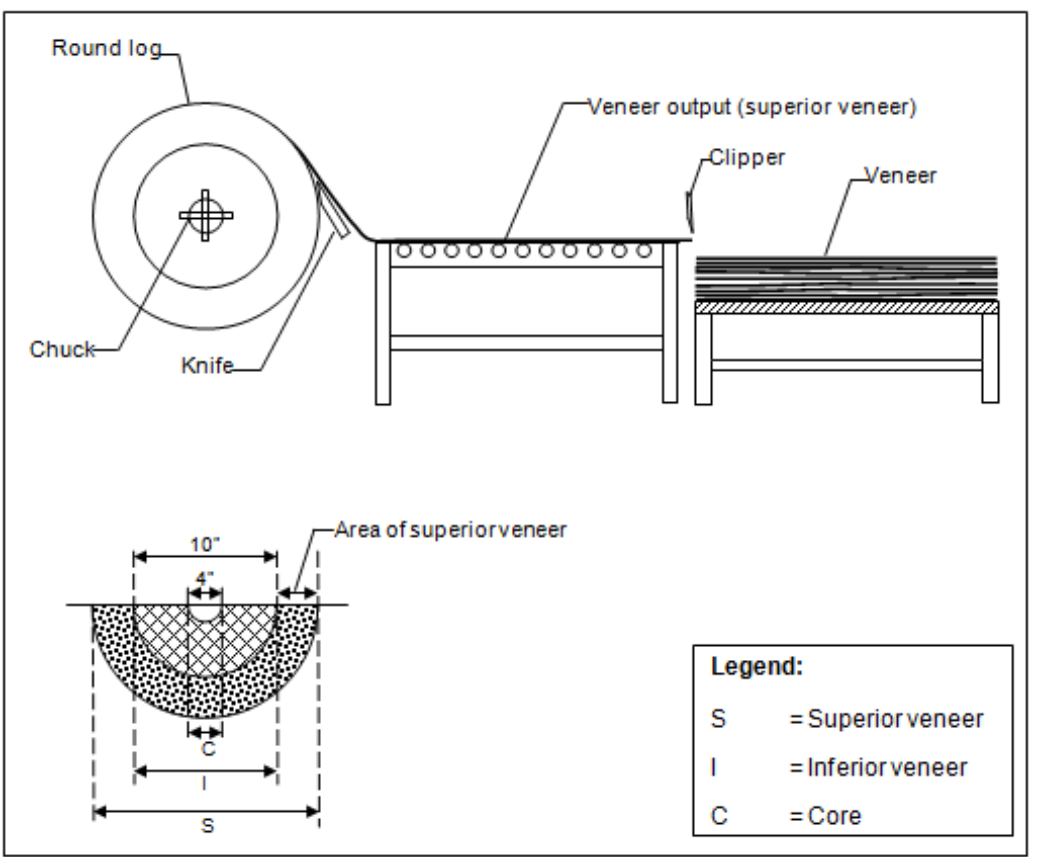

Figure 3. Peeling processes to obtain superior and inferior veneers 


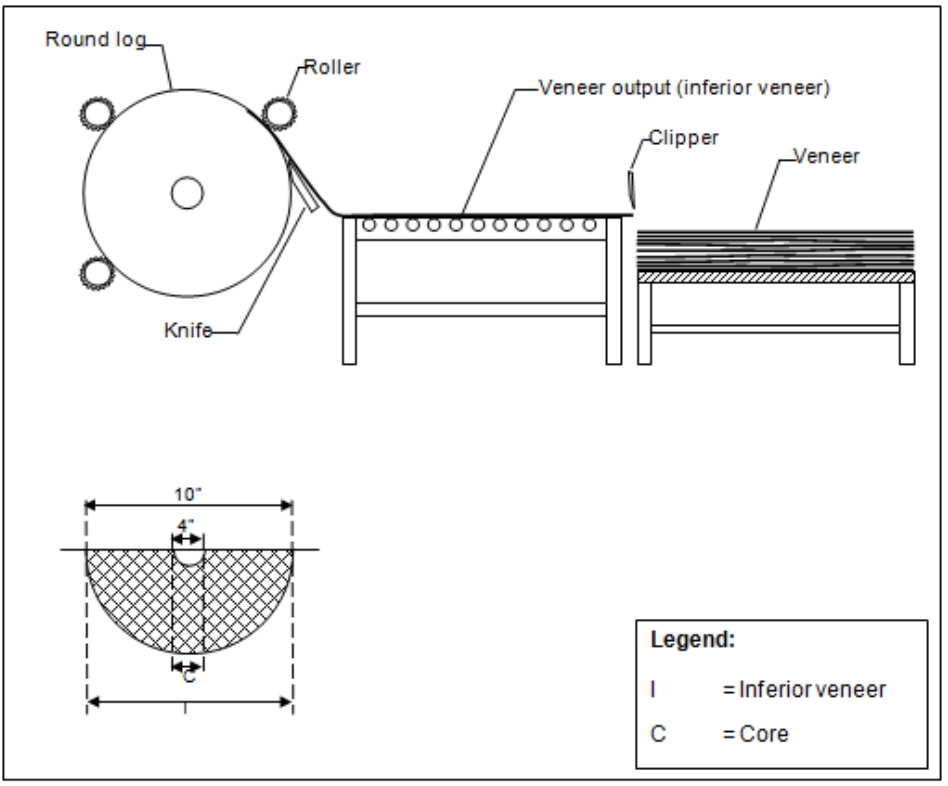

Figure 4. Peeling processes to obtain superior and inferior veneers

\subsection{Fabrication of MLVOPS Made from Superior and Inferior Veneers}

The oven-dried veneers were divided into 3 different combinations such as $\mathrm{S} 100 \%$ (each ply came from the superior part), SS-CI (surface superior and core inferior) and S-I (alternate superior and inferior parts). The veneers were then used to produce 5-ply laminated veneer profiles. The veneers were arranged as exhibited in Figure 5. The thickness of the veneers after they were dried was between $3.0 \mathrm{~mm}-3.5 \mathrm{~mm}$. The arranged veneers were segregated into two groups. The first group was spread with UF resin and the second one was spread with PF resin. And then, veneers were re-arranged to the combinations after the application of resin to prevent confusion. The groups were further divided into three smaller groups as they were hot-pressed separately with three different pressing pressures i.e. 1500psi, 2000psi and 2500psi. The moulding process was done during the hot pressing. Pressing time and temperature for each group were standardized according to the industrial practices. The pressing time and temperature were $20 \mathrm{~min}$ and $110^{\circ} \mathrm{C}$ respectively. One combination of veneers was hot pressed at a time. Sufficient hot pressing time and temperature is important to encourage the curing of the resins. Once the hot-pressing process has settled, the composite was removed from the hot pressing machine and they were exposed to the surrounding to stabilize the temperature of the composite and accelerate the cure of the resin. The fabricated composites were then conditioned in a conditioning room at a temperature of $20 \pm 2^{\circ} \mathrm{C}$ and $65 \pm 5 \%$ relative humidity $(\mathrm{RH})$ for a week. The conditioned composites were trimmed to specified dimensions according to BS EN 408:1995 for screw withdrawal tests. Thirty samples were utilized for each group (with regards to veneer arrangements and pressing pressures).

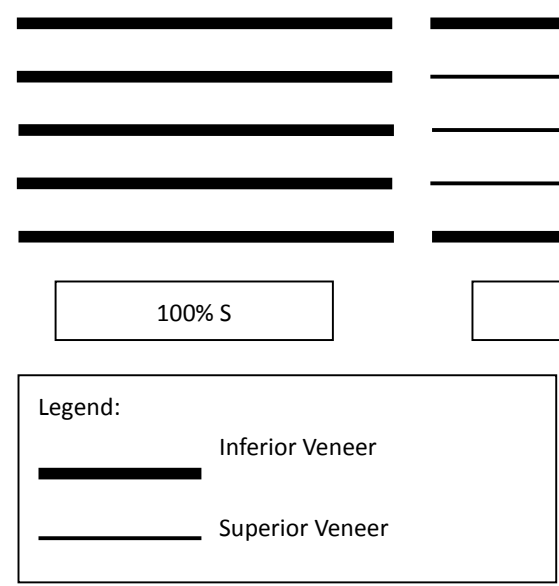

Figure 5. Veneer arrangements for three different groups of laminated profiles 


\subsection{Screw Withdrawal Test}

One of the most important factors to evaluate panel products whether they are suitable for building construction material is the ability to resist screw withdrawal. Firstly, the test was done by cutting the laminated veneer lumber into samples with a dimension of $50 \times 50 \mathrm{~mm}$. One sample was tested at a time. Secondly, the sample was drilled at its centre before a screw with a size of $38 \mathrm{~mm}$ long and $3 \mathrm{~mm}$ diameter screw was pressed into the sample through the pre-drilled guide hole. With a special jig equipped on the Instron machine, the head of the screw was "pulled" to failure at a constant speed of $15 \mathrm{~mm} / \mathrm{min}$. The "pulled" maximum load (N) was recorded as the withdrawal strength. The test is summarized in Figure 6.

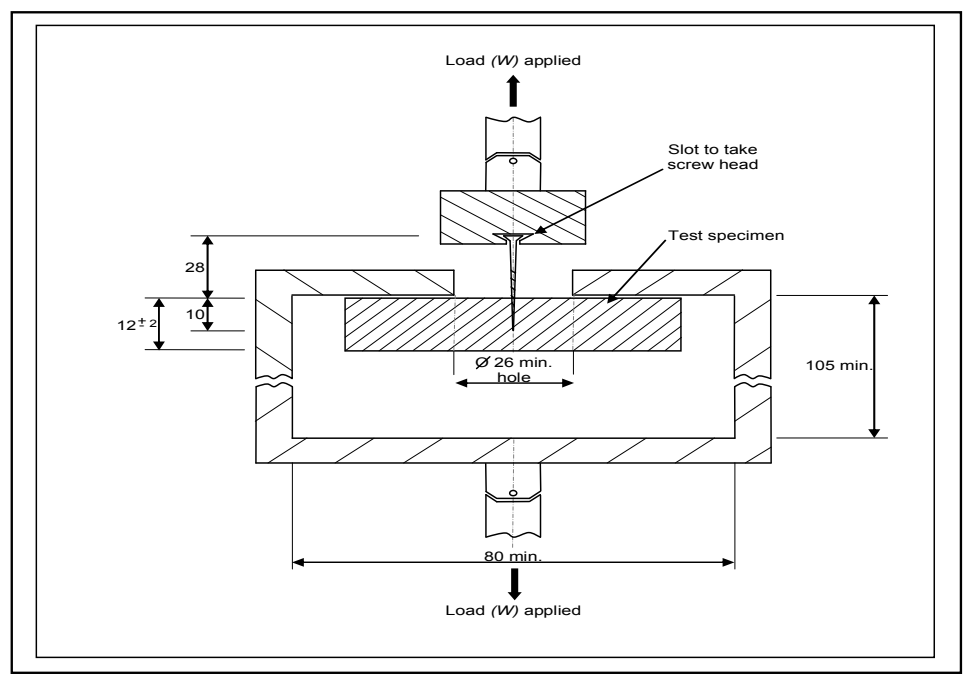

Figure 6. Screw Withdrawal Test

\subsection{Data Analysis}

All the data were analysed using one-way analysis of variance to determine the differences in properties between pressing pressures and veneer arrangements.

\section{Results}

The outcomes of the screw withdrawal test are given in Table 1 and 2. Higher strength value implies higher resistance against screw withdrawal.

Table 1. Screw withdrawal resistance of MLVOP using UF resin

\begin{tabular}{|c|c|c|}
\hline $\begin{array}{c}\text { Veneer } \\
\text { arrangements }\end{array}$ & Pressure $(\mathrm{Pa})$ & $\begin{array}{l}\text { Screw withdrawal } \\
\text { resistance }(\mathrm{N})\end{array}$ \\
\hline $\mathrm{S} 100 \%^{\mathrm{a}}$ & & 570 \\
\hline $\mathrm{SS}-\mathrm{CI}^{\mathrm{a}}$ & $10342135.94^{\mathrm{a}}$ & 540 \\
\hline S-I ${ }^{b}$ & & 848 \\
\hline $\mathrm{S} 100 \%^{\mathrm{a}}$ & & 586 \\
\hline $\mathrm{SS}-\mathrm{CI}^{\mathrm{a}}$ & $13789514.59^{\mathrm{b}}$ & 845 \\
\hline S-I ${ }^{b}$ & & 770 \\
\hline $\mathrm{S} 100 \%^{\mathrm{a}}$ & & 576 \\
\hline $\mathrm{SS}-\mathrm{CI}^{\mathrm{a}}$ & $17236893.23^{c}$ & 670 \\
\hline S-I ${ }^{b}$ & & 884 \\
\hline
\end{tabular}

Means with the same letter are not significantly different at $\alpha=0.05$ by Duncan - Waller-Duncan Test 
Table 2. Screw withdrawal resistance of MLVOP using PF resin

\begin{tabular}{ccc}
\hline $\begin{array}{c}\text { Veneer } \\
\text { arrangements }\end{array}$ & Pressure (Pa) & $\begin{array}{c}\text { Screw withdrawal } \\
\text { resistance (N) }\end{array}$ \\
\hline S100\% a & & 402 \\
SS-CI b & $10342135.94 \mathrm{a}$ & 416 \\
S-I c & & 496 \\
S100\% a & & 591 \\
SS-CI b & $13789514.59 \mathrm{a}$ & 693 \\
S-I c & & 542 \\
S100\% a & & 592 \\
SS-CI b & $17236893.23 \mathrm{a}$ & 439 \\
S-I c & & 441
\end{tabular}

Means with the same letter are not significantly different at $\alpha=0.05$ by Duncan - Waller-Duncan Test; S.V.= standard value

\section{Discussion}

\subsection{Screw Withdrawal Resistance of MLVOP Treated with UF Resin}

The average screw withdrawal resistance values of MLVOP fabricated using UF resin were significantly affected by pressing pressures and veneer arrangements. However veneer arrangements of S100\% and SS-CI were found to give insignificant difference to the average screw withdrawal values. For MLVOP pressed with 1500 psi, changing veneer arrangements resulted in inconsistency of average screw withdrawal resistance values. The average screw withdrawal resistance values decreased from $570 \mathrm{~N}$ to $540 \mathrm{~N}$ as the veneer arrangements were changed from $\mathrm{S} 100 \%$ to SS-CI respectively. The average screw withdrawal resistance value was greater $(840 \mathrm{~N})$ when the veneers were arranged with S-I arrangement. As for MLVOP pressed with 2000 psi, like those pressed with $1500 \mathrm{psi}$, the average screw withdrawal resistance values were found inconsistent when the veneer arrangements were changed from S100\% to S-I respectively. The lowest value was recorded from S100\% (586 $\mathrm{N})$. The greatest value was obtained from SS-CI arrangement $(845 \mathrm{~N})$. The value for S-I arrangement was $770 \mathrm{~N}$. A consistent result was observed when the MLVOP was fabricated with a pressing pressure of 2500 psi. Changing veneer arrangements resulted in increase of the average screw withdrawal resistance value. The average screw withdrawal resistance values for veneer arrangements; S100\%, SS-CI and S-I were 576 N, $670 \mathrm{~N}$ and $884 \mathrm{~N}$ respectively.

\subsection{Screw Withdrawal Resistance of MLVOP Treated with PF Resin}

Table 2 revealed a comparison of screw withdrawal resistance values of MLVOP bonded with PF resin at different veneer arrangements and pressures. The results indicated that the screw withdrawal resistance values were significantly affected by veneer arrangements but not by pressing pressures. For the samples manufactured from 1500 psi pressing pressure, the highest average screw withdrawal resistance value was obtained from samples with S-I veneer arrangement i.e $496 \mathrm{~N}$. The average screw withdrawal values for the other two veneer arrangements namely S100\% and SS-CI were $402 \mathrm{~N}$ and $416 \mathrm{~N}$ respectively. Inconsistent results were recorded from samples produced with the pressing pressure of $2000 \mathrm{psi}$. The average screw withdrawal resistance values for S100\%, SS-CI and S-I veneer arrangements were $593 \mathrm{~N}, 693 \mathrm{~N}$ and $542 \mathrm{~N}$ respectively. When the samples were fabricated with the pressing pressure of $2500 \mathrm{psi}$, the average screw withdrawal resistance values were 592 $\mathrm{N}, 439 \mathrm{~N}$ and $441 \mathrm{~N}$ respectively. By comparing the results of PF-bonded MLVOP samples with those bonded with UF resin, it seems that the results of those bonded with UF were superior to those bonded with PF. Perhaps, this is due to the pressing duration occupied for PF-bonded samples which was similar to pressing duration for UF-bonded samples. A correct pressing duration is important to get sufficient curing of the resin and establishing good interfacial bonding between veneers and resin. A good interfacial bonding can help to improve screw withdrawal resistance (Shannag et al., 1997). UF resin is a resin that can cure fast; thus it requires shorter 
pressing pressure to cure. Conversely, PF resin is curing slower; hence it requires longer pressing pressure than UF resin (Anon, 2010). Longer pressing duration than actual pressing duration may cause the resins becomes too cured and cause bonding becomes ineffective. Normally, curing time of a resin can be determined by conducting a test called curing test (Izran et al., 2010). Thereupon, modification of the pressing duration for PF-bonded samples need to be done by either shorten or prolong its pressing duration. In case the pressing duration is too long, it can be shortened by raising the pressing temperature. Moreover, it is expected that the screw withdrawal resistance value may be better if the screws are put into the samples by turn them in instead of forcing them in by pressing. It is because it tears the wood fibres and injures the screw threads which then reducing load carrying capacity of the screw (Soltis, 1999). For this research, the screws were pressed into the samples. This could be improved for future research or testing. With regards to veneer arrangement, the S-I combination gave significant effects to the screw withdrawal resistance values, even though the means obtained from the samples made with this combination were lower than one or both of the other combinations. For example, UF-bonded MLVOPs with 2000 psi pressing pressure, PF-bonded MLVOPs pressed with 2000 psi and 2500 psi. The values were $845 \mathrm{~N}$, $542 \mathrm{~N}$ and $441 \mathrm{~N}$ respectively. MLVOPs with this combination achieved the highest values when they were produced with UF resin then pressed at $1500 \mathrm{psi}$ and $2500 \mathrm{psi}$ and PF resin then pressed at $1500 \mathrm{psi}$. The means were $848 \mathrm{~N}, 884 \mathrm{~N}$ and $496 \mathrm{~N}$ respectively. The results indicate that pressing pressure did affect the effect of veneer arrangement to achieve good lamination and screw withdrawal resistance. Too much pressing can reduce the screw withdrawal resistance. The research revealed that the 2000 psi pressing pressure was not suitable for S-I veneer arrangement. Perhaps, the pressure was not sufficient enough to improve contact between the veneer surfaces and the adhesive, hence caused weak screw withdrawal resistance. This can be improved by increasing the pressing temperature or lengthening the pressing duration because, higher pressing temperature can speed up the curing of the resin. However the drawback of this solution is, it may scorch the pressed veneers and cause worse physical and mechanical properties of the MLVOPs.

In conclusion, screw withdrawal resistance of MLVOPs made of different veneer arrangements, bonded with different formaldehyde resins and pressed with different pressing pressures were measured. It was shown that the pressing pressures gave significant effects to the screw withdrawal resistance of the MLVOPs. Veneer arrangement gave insignificant effect to the screw withdrawal resistance except S-I veneer arrangement. MLVOPs bonded with UF resin performed better than those bind with PF resin. The data are useful in developing correction factors for the effects of pressing pressure, resin type and veneer arrangement on screw withdrawal resistance in the production of furniture-grade MLVOP.

\section{References}

Anonymous. (2010). Fibreboard. Wikipedia-The Free Encyclopedia. Retrieved from http://en.wikipedia.org/wiki/Fiberboard

ASTM D1761-06. (2006). Standard Test Methods For Mechanical Fasteners in Wood. United States ofAmerica.

Buckley, K. (2011). Benefits of Laminated Veneer Lumber. Retrieved from http://ezinearticles.com/?Benefits-of-Laminated-Veneer-Lumber\&id=3987806

Eckelman, C. (1990). Fasteners And Their Use in Particleboard and Medium Density Fibreboard. National Particleboard Association, Purdue University.

Hng, P. S., Paridah, M. T., \& Gan, C. W. (2007). Flexural Properties of Laminated Veneer LumberManufactured from Oil Palm Veneers. PERTANIKA, 30(1), 65-70.

Izran, K., Koh, M. P., Tan, Y. E., Ren, X. J., Zaidon, A., Abood, F., ... Khairul, M. (2010). Buffering Capacity of Fast Growing Species and Curing Time of UF Resin Modified With Zinc Borate and Monoammonium

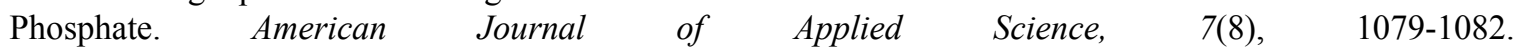
http://dx.doi.org/10.3844/ajassp.2010.1079.1082

Jegatheswaran, R. (2011). Permanfaatan Biomassa Kelapa Sawit-Laporan Keberhasilan Di Malaysia. Retrieved from

http://www.woodmagmagazine.com/features/pemanfaatan-biomassa-kelapa-sawit---laporan-kebrhasilan-dimalaysia

Kamarulzaman, N., Mohd. Ariff, J., Mansur, A., Hashim, W. S., Abdul Hamid, S., \& Zaihan, J. (2004). Minimizing the environmental burden of oil palm trunk residues through the development of laminated veneer lumber products. Management of Environmental Quality: An International Journal, 5(5), 484-490.

Razak, W., Hashim, W. S., Azmy, M., \& Othman, S. (2008). Utilization Potential of 30 Year Old Oil Palm Trunks Laminated Veneer Lumbers of Non Structural Purposes. Journal of Sustainable Development, 1(3), 
109-113.

Shannag, M. J., Brincker, R., \& Hansen, W. (1997). Pullout Behaviour of Steel Fibers from Cement-Based Composites. Journal of Cement and Concrete Research, 27(6), 925-936. http://dx.doi.org/10.1016/S0008-8846(97)00061-6

Soltis, A. (1999). Fastenings, Chapter 7, Wood Handbook - Wood as an engineering material, General Technology Report. FPL-GTR-113, Madison, WI: US Department of Agriculture, Forest Service, Forest Products Laboratory, p. 463. 